\title{
Introduction to Chapter 4
}

Bomuhangi et al. have accomplished something many ACM practitioners and researchers have wanted, but been unable, to do: They have compared forest use and management in eight purposively sampled places around Uganda, looking at three important issues. The first is clarity about the various uses to which these communities put forests. The second is the differentiation by gender in terms of use, management, and benefits. In this regard, the authors show the greater involvement of women in ACM sites, vis a vis where ACM was not conducted. The third is a systematic comparison of a variety of results in ACM vs. non-ACM sites. These include issues like level and quality of participation, perceived abundance of forest resources, harvest of forest products, and use thereof. The authors conclude by recommending the broader use of ACM-like approaches throughout Uganda's forested areas, in collaboration with government, NGOs, and private landowners.

A few of the interesting findings that emerge here include: 1) the greater sense these Ugandan women have of their own involvement in public vs. private forest management; 2) the powerful impact of husbands' support on women's involvement in forest management; and 3) the comparative irrelevance of women's educational level in forest management.

One purpose behind the conduct of this research was to provide an assessment that would be convincing to and useful for policymakers at the national level. The analysis is succinct, well rounded, and convincing; and they are able to present much of their findings in tabular form -- appealing to many policymakers with little time to read. This chapter also sets the stage for the following chapter (5), which presents the ways ACM was conducted in the communities compared here. 